\title{
Lee W. Gregg: In Appreciation
}

This issue of Behavior Research Methods \& Instrumentation is dedicated to the memory of Lee William Gregg, age 54, who died on June 4, 1980, in Pittsburgh, Pennsylvania. Dr. Gregg served as a president of the National Conference for the Use of On-Line Computers in Psychology and as a member of the steering committee; he was influential in the development of the organization.

At the time of his death, Lee Gregg was head of the Department of Psychology at Carnegie-Mellon University and Associate Dean of the University's College of Humanities and Social Sciences. Lee Gregg affiliated with Carnegie-Mellon in 1952 and dedicated his services to that institution until his death. He received his Bachelor of Science degree from Northwestern University in 1948 and his master's and doctorate from the University of Wisconsin at Madison in 1952. As Department Head since 1973, Dr. Gregg had a great influence in the program he developed into one of the finest cognitive psychology programs in the country. Lee
Gregg's background in electronics and computer technology could be matched by few in the field of psychology. There were few developments in the computer phase of the behavioral sciences with which he was not familiar, and he shared that knowledge with all who sought it. Lee was a strong man who expressed his opinions freely and who loved to be involved in movement and to make things move. He formulated his own ideas concerning computers, from number crunchers to micros. Lee W. Gregg was also my friend and for that I'm most thankful. We who knew him well know our personal loss. Organizations with which he was affiliated will miss his drive, his intellect, his aid, and his forthrightness when necessary and when the goals were worthwhile. It is fitting that this volume of computer proceedings be dedicated to an individual whose actual academic life was associated throughout, in one way or another, with instrumentation and technology.

Joseph B. Sidowski 